\title{
Optimum Failure-Censored Step-Stress Life Test Plans for the Lomax Distribution
}

\author{
Ali A. Ismail ${ }^{\text {a,b }}$ \\ ${ }^{a}$ King Saud University, College of Science, Department of Statistics and Operations Research, P.O. \\ BOX 2455, Riyadh 11451, Saudi Arabia \\ ${ }^{\mathrm{b}}$ Cairo University, Faculty of Economics \& Political Science, Department of Statistics, Giza 12613, \\ Egypt \\ aismail100@yahoo.com (Ali A. Ismail)
}

УДК 539.4

\section{Оптимальное планирование частично ускоренных ресурсных испытаний с цензурированием разрушения по времени для распределения Ломакса}

\author{
Али А. Исмаил ${ }^{\mathrm{a}, \boldsymbol{0}}$ \\ а Университет им. короля Сауда, Эр-Риад, Саудовская Аравия \\ ${ }^{\sigma}$ Каирский университет, Гиза, Египет
}

Рассматриваются частично ускоренные ресурсные испытания при пошаговом изменении напряжений, при которых постулируется, что время до разрушения характеризуется распределением Ломакса при иензурировании разрушения. Получены показатели максимальной вероятности параметров данной модели и соответствующие среднеквадратичные отклонения, $a$ также рассчитаны доверительные интерваль параметров с соответствующими вероятностями покрытия. Изучены оптимальные варианты проведения ресурсных испытаний. Для верификации полученных теоретических результатов выполнено численное моделирование тестовых задач.

Ключевые слова: напряжение, распределение Ломакса, частичное ускорение, оценка интервала, вероятность покрытия, оптимальный план испытаний, цензурирование по типу II, уравнения Ньютона-Рафсона, нелинейность, моделирование по методу МонтеКарло.

Introduction. To quickly obtain failures of highly-reliable modern electronic systems, exceptional testing methods identified as accelerated life tests (ALT) are applied. In an ALT, the pieces are run under conditions far harsher than those met in practice. Standing or suggested life-stress model that relate the stress level to the parameters of life distribution are then applied to induce the observed results under design stress. In such tests, either time is compacted, in which a device is applied more repeatedly than it would be in the normal setting, while the loads and stresses are retained at their ordinary levels, or loads on the device are increased to gain failures in a shorter time period. (For more details, see [1].)

However, if the life-stress relationship can not be assumed, ALT can't be applied. In such cases partially accelerated life test (PALT) come to be a good alternative instead of ALT. As indicated by Ismail [2-4], ALT and PALT are commonly used in up-to-date industrial engineering to save time and cost.

As mentioned by Nelson [5], the loads can be used in many techniques. One approach used to hasten failure is the step-stress. This article studies the step-stress PALT (SSPALT), in which a test specimen is first run at design stress and, if it does not fail for an identified 
time $\tau$, then it is run faster until failure occurs or the observation is terminated. As Bhattacharyya and Soejoeti [6] have indicated, the step-stress PALT is useful for numerous applications of life testing.

There is a vast literature on SSPALT. Goel [7] discussed the estimation process of the acceleration factor $\beta$ by means of the maximum likelihood approach for pieces having the exponential distribution and uniform distribution under complete sampling. Also, he got the optimal test designs. DeGroot and Goel [8] studied the following SSPALT model: $Y=T$ if $T \leq \tau$ and $Y=\tau+\beta^{-1}(T-\tau)$ if $T>\tau$, where $T$ is the lifetime of an specimen under design stress and $Y$ is its total lifetime. Bhattcharyya and Soejoeti [6] suggested a failure-rate model, in which $h^{\prime}(y)=h(y)$ if $y \leq \tau$ and $h^{\prime}(y)=\beta h(y)$ if $y>\tau$, where $h($.$) and h^{\prime}($.$) are failure rate functions of T$ and $Y$, respectively. Also, Bhattcharyya and Soejoeti [6] found the estimates of the model parameters by the maximum likelihood procedure under full sampling when $T$ follows the Weibull distribution.

Using type-I censored data, some works on PALT have been conducted. For example, Bai and Chung [9] applied the maximum likelihood technique to estimate the scale parameter and the acceleration factor for exponentially distributed lifetime. They also discussed the problem of optimally designing the SSPALT that terminates at a fixed time. Bai et al. [10] extended the same work of Bai and Chung [9] to the case of pieces having the lognormal distribution. Abdel-Ghaly et al. [11] used the maximum likelihood way for estimating the acceleration factor and parameters of the Weibull distribution. Ismail [12] discussed the estimation process of the generalized exponential distribution parameters and the acceleration factor under progressive type-II censoring. Ismail [13] developed test plans of time-step PALTs under the Weibull distribution with a failure-censoring scheme. Also, Srivastava and Mittal [14] studied the optimum step-stress PALTs under the truncated logistic distribution using type-I and type-II censored data. This article addresses the optimum failure-censored PALT plans under the Lomax model.

This article is structured as follows. The Lomax distribution as a lifetime model is presented in Section 1. Section 2 contains the derivation of both maximum likelihood estimates (MLE) of the Lomax distribution parameters and the acceleration factor and the confidence bounds of the model parameters. Section 3 considers the ptimum step-stress PALT plans under failure-censoring. To clarify the theoretical results, simulation studies are provided in Section 4. Finally, some concluding remarks are presented in Section 5.

1. Model. In this article, it is assumed that the life distribution is the Lomax one. The probability density function of this distribution is expressed by

$$
f_{T}(t ; \theta, \alpha)=\frac{\alpha \theta^{\alpha}}{(\theta+t)^{\alpha+1}}, \quad t>0, \quad \theta>0, \quad \alpha>0 .
$$

The reliability function is given by

$$
R(t)=\frac{\theta^{\alpha}}{(\theta+t)^{\alpha}} .
$$

The failure-rate function is

$$
h(t)=\frac{\alpha}{\theta+t}
$$

which is a decreasing function as $t>0$, indicating the early failure stage. According to Martz [1], this type of failures may be due to initial defects, bad assembly or poor fits, etc. Hence, as indicated by Abdel-Ghaly et al. [15], the Lomax distribution may be applied as a reliability growth model. 
Grimshaw [16] used the Lomax distribution to model tensile-strength data from a random sample of nylon carpet fibers. Also, as stated by Davis and Feldstein [17] and AbdelGhaly et al. [15], it has been used in connection with reliability theory and survival analysis.

2. ML Estimation. As shown by Grimshaw [16], the ML technique is usually applied for most theoretical models and styles of censored data. Also, Bugaighis [18] indicated that the maximum likelihood technique mostly provides efficient estimators.

The probability density function of the total lifetime $Y$ of an item in SSPALT is set by

$$
f(y)= \begin{cases}0 & y \leq 0, \\ \frac{\alpha \theta^{\alpha}}{(\theta+y)^{\alpha+1}} & 0<y \leq \tau, \\ \frac{\beta \alpha \theta^{\alpha}}{[\theta+\tau+\beta(y-\tau)]^{\alpha+1}} & y>\tau .\end{cases}
$$

The experimental values of the total lifetime $Y$ are expressed by

$$
y_{(1)} \leq \ldots \leq y_{(n u)} \leq \tau \leq y_{(n u+1)} \leq \ldots \leq y_{(r)} .
$$

Let $\delta_{1 i}$ and $\delta_{2 i}$ be indicator functions such that $\delta_{1 i} \equiv I\left(Y_{i} \leq \tau\right)$ and $\delta_{2 i} \equiv$ $\equiv I\left(\tau<Y_{i} \leq y_{(r)}\right)$.

The natural logarithm of the total likelihood function is set by

$$
\begin{aligned}
& \ln L=r \ln \alpha+n \alpha \ln \theta+n_{a} \ln \beta-(n-r) \alpha \ln \left(\theta+\tau+\beta\left(y_{(r)}-\tau\right)\right)- \\
& -(\alpha+1)\left[\sum_{i=1}^{n} \delta_{1 i} \ln \left(\theta+y_{i}\right)+\sum_{i=1}^{n} \delta_{2 i} \ln \left(\theta+\tau+\beta\left(y_{i}-\tau\right)\right)\right] .
\end{aligned}
$$

The first derivatives of the function in (5) with respect to the three parameters are obtained as

$$
\frac{\partial \ln L}{\partial \beta}=\frac{n_{a}}{\beta}-\frac{(n-r) \alpha\left(y_{(r)}-\tau\right)}{\psi_{r}}-(\alpha+1) \sum_{i=1}^{n} \delta_{2 i} \frac{\left(y_{i}-\tau\right)}{\psi_{i}},
$$

where

$$
\begin{gathered}
\psi_{r}=\theta+\tau+\beta\left(y_{(r)}-\tau\right) \quad \text { and } \quad \psi_{i}=\theta+\tau+\beta\left(y_{(i)}-\tau\right), \\
\frac{\partial \ln L}{\partial \theta}=\frac{n \alpha}{\theta}-\frac{(n-r) \alpha}{\psi_{r}}-(\alpha+1)\left[\sum_{i=1}^{n} \frac{\delta_{1 i}}{\left(\theta+y_{i}\right)}+\sum_{i=1}^{n} \frac{\delta_{2 i}}{\psi_{i}}\right], \\
\frac{\partial \ln L}{\partial \alpha}=\frac{r}{\alpha}+n \ln \theta-(n-r) \ln \psi_{r}-\sum_{i=1}^{n} \delta_{1 i} \ln \left(\theta+y_{i}\right)-\sum_{i=1}^{n} \delta_{2 i} \ln \psi_{l} .
\end{gathered}
$$

The ML estimate of $\alpha$ can be obtained from Eq. (8) as follows:

$$
\hat{\alpha}=\frac{r}{(n-r) \ln \psi_{r}-n \ln \hat{\theta}+\sum_{i=1}^{n} \delta_{1 i} \ln \left(\hat{\theta}+y_{i}\right)+\sum_{i=1}^{n} \delta_{2 i} \ln \psi_{i}} .
$$


Thus, the system equations are reduced to the following form:

$$
\frac{n_{a}}{\hat{\beta}}-\frac{r(n-r)\left(y_{(r)}-\tau\right)}{Q_{1} \psi_{r}}-\left(\frac{r}{Q_{1}}+1\right) \sum_{i=1}^{n} \delta_{2 i} \frac{\left(y_{i}-\tau\right)}{\psi_{i}}=0
$$

and

$$
\frac{n r}{Q_{2}}-\frac{r(n-r)}{Q_{1} \psi_{r}}-\left(\frac{r}{Q_{1}}+1\right)\left[\sum_{i=1}^{n} \frac{\delta_{1 i}}{\left(\hat{\theta}+y_{i}\right)}+\sum_{i=1}^{n} \frac{\delta_{2 i}}{\psi_{i}}\right]=0,
$$

where

$$
Q_{1}=(n-r) \ln \psi_{r}-n \ln \hat{\theta}+\sum_{i=1}^{n} \delta_{1 i} \ln \left(\hat{\theta}+y_{i}\right)+\sum_{i=1}^{n} \delta_{2 i} \ln \psi_{i},
$$

and

$$
Q_{2}=\hat{\theta}(n-r) \ln \psi_{r}-n \ln \hat{\theta}+\sum_{i=1}^{n} \delta_{1 i} \ln \left(\hat{\theta}+y_{i}\right)+\sum_{i=1}^{n} \delta_{2 i} \ln \psi_{i}
$$

The above nonlinear system is solved by applying the Newton-Raphson technique.

Now, for constructing the confidence bounds of the parameters, the second partial derivatives of the function in (5) are needed in this respect, which can be given by

$$
\begin{gathered}
\frac{\partial^{2} \ln L}{\partial \beta^{2}}=-\frac{n_{a}}{\beta^{2}}+\frac{(n-r) \alpha\left(y_{(r)}-\tau\right)^{2}}{\psi_{r}^{2}}+(\alpha+1) \sum_{i=1}^{n} \delta_{2 i} \frac{\left(y_{i}-\tau\right)^{2}}{\psi_{i}^{2}}, \\
\frac{\partial^{2} \ln L}{\partial \theta^{2}}=-\frac{n \alpha}{\theta^{2}}+\frac{(n-r) \alpha}{\psi_{r}^{2}}+(\alpha+1)\left[\sum_{i=1}^{n} \frac{\delta_{1 i}}{\left(\theta+y_{i}\right)^{2}}+\sum_{i=1}^{n} \frac{\delta_{2 i}}{\psi_{i}^{2}}\right] \\
\frac{\partial^{2} \ln L}{\partial \alpha^{2}}=-\frac{r}{\alpha^{2}} \\
\frac{\partial^{2} \ln L}{\partial \beta \partial \theta}=\frac{(n-r) \alpha\left(y_{(r)}-\tau\right)}{\psi_{r}^{2}}+(\alpha+1) \sum_{i=1}^{n} \delta_{2 i} \frac{\left(y_{i}-\tau\right)}{\psi_{i}^{2}} \\
\frac{\partial^{2} \ln L}{\partial \beta \partial \alpha}=-\frac{(n-r)\left(y_{(r)}-\tau\right)}{\psi_{r}}-\sum_{i=1}^{n} \delta_{2 i} \frac{\left(y_{i}-\tau\right)}{\psi_{i}} \\
\frac{\partial^{2} \ln L}{\partial \theta \partial \alpha}=\frac{n}{\theta}-\frac{(n-r)}{\psi_{r}}-\left[\sum_{i=1}^{n} \frac{\delta_{1 i}}{\left(\theta+y_{i}\right)}+\sum_{i=1}^{n} \frac{\delta_{2 i}}{\psi_{i}}\right]
\end{gathered}
$$

3. Test Plan. Optimum Stress Switching-Time $\tau^{*}$. In this section, the optimal SSPALT designs are established under the failure-censoring scheme. That is, the optimum stress switching-time $\tau^{*}$ is found such that the generalized asymptotic variance (GAV) of MLEs of the model parameters at design stress is minimized. 
As defined by Bai et al. [19] the GAV of the MLEs of the model parameters is the reciprocal of the determinant of $F$. That is

$$
\operatorname{GAV}(\hat{\beta}, \hat{\theta}, \hat{\alpha})=\frac{1}{|F|}
$$

The optimum stress switching-time $\tau^{*}$ that minimizes the GAV defined above can be obtained by using the Newton-Raphson technique.

4. Simulation Studies. Using different parameters values settings from Lomax distribution and different sample sizes 30,40, 50, 75, and 100 with 10,000 replications, optimum test plans are numerically obtained. Two populations are used in this study with parameter values $(3,2,1.5)$ and $(2,3,0.6)$. To evaluate the performance of the MLEs, mean square error (MSE), average confidence intervals lengths (IL) and the associated coverage probabilities (CP) were calculated as shown from the numerical results. In addition, the optimum value $\tau^{*}$, the optimum expected number of units failed at each stress level, and the optimum value of GAV were also derived (Tables 1-4).

The numerical results show that the MLEs are close to the right values as $n$ increases. Also, as $n$ increases, the MSE decreases. In addition, the confidence bounds of the parameters are getting much narrower if the sample size $n$ increases. It is also observed that the CP for each parameter is close to the nominal confidence level. That is, the procedure is quite successfull.

Moreover, the optimum design of SSPALT is developed. The results showed that the SSPALT model is appropriate. The optimal GAV decreases as $n$ increases.

$\mathrm{T}$ a b 1 e 1

MLEs, MSE, and IL95\% on Average with Parameters $(\beta, \theta, \alpha)$ Set at $(3,2,1.5)$, Respectively, Using $\tau=7$ with $r=0.75 n$

\begin{tabular}{|c|c|c|c|c|c|}
\hline$n$ & Parameter & Estimate & MSE & IL95\% & $95 \% \mathrm{CP}$ \\
\hline \multirow[t]{3}{*}{30} & $\beta$ & 3.3536 & 0.0394 & 0.4627 & 0.9481 \\
\hline & $\theta$ & 2.3335 & 0.0588 & 1.0683 & 0.9546 \\
\hline & $\alpha$ & 1.6685 & 0.0292 & 0.2385 & 0.9564 \\
\hline \multirow[t]{3}{*}{40} & $\beta$ & 3.2810 & 0.0281 & 0.3401 & 0.9605 \\
\hline & $\theta$ & 2.2661 & 0.0349 & 1.0515 & 0.9533 \\
\hline & $\alpha$ & 1.5897 & 0.0121 & 0.1441 & 0.9528 \\
\hline \multirow[t]{3}{*}{50} & $\beta$ & 3.1838 & 0.0179 & 0.1736 & 0.9492 \\
\hline & $\theta$ & 2.1435 & 0.0232 & 0.5283 & 0.9517 \\
\hline & $\alpha$ & 1.5465 & 0.0009 & 0.1012 & 0.9524 \\
\hline \multirow[t]{3}{*}{75} & $\beta$ & 3.0702 & 0.0133 & 0.0878 & 0.9554 \\
\hline & $\theta$ & 2.0617 & 0.0156 & 0.2131 & 0.9502 \\
\hline & $\alpha$ & 1.5045 & 0.0004 & 0.0434 & 0.9511 \\
\hline \multirow[t]{3}{*}{100} & $\beta$ & 3.0121 & 0.0081 & 0.0480 & 0.9519 \\
\hline & $\theta$ & 1.9946 & 0.0117 & 0.1573 & 0.9502 \\
\hline & $\alpha$ & 1.4902 & 0.0002 & 0.0199 & 0.9507 \\
\hline
\end{tabular}


$\mathrm{T}$ a b 1 e 2

The Optimal $\tau^{*}$ and GAV Values Based on the Results from Table 1

\begin{tabular}{|c|c|c|c|c||}
\hline$n$ & $\tau^{*}$ & $n P_{u}$ & $n P_{a}$ & Optimal GAV \\
\hline 30 & 22.4877 & 14 & 9 & 0.0180 \\
\hline 40 & 22.1819 & 18 & 12 & 0.0085 \\
\hline 50 & 22.0901 & 23 & 15 & 0.0043 \\
\hline 75 & 21.5479 & 34 & 22 & 0.0016 \\
\hline 100 & 22.1196 & 45 & 30 & 0.0005 \\
\hline
\end{tabular}

T a b 1 e 3

MLEs, MSE, and IL95\% on Average with Parameters $(\beta, \theta, \alpha)$ Set at $(2,3,0.6)$,

Respectively, Using $\tau=7$ with $r=0.75 n$

\begin{tabular}{|c|c|c|c|c|c|}
\hline$n$ & Parameter & Estimate & MSE & IL95\% & $95 \% \mathrm{CP}$ \\
\hline \multirow[t]{3}{*}{30} & $\beta$ & 2.4618 & 0.249 & 0.5042 & 0.9491 \\
\hline & $\theta$ & 3.3106 & 0.0371 & 1.1638 & 0.9523 \\
\hline & $\alpha$ & 0.8591 & 0.0184 & 0.2599 & 0.9522 \\
\hline \multirow[t]{3}{*}{40} & $\beta$ & 2.3447 & 0.0178 & 0.3706 & 0.9515 \\
\hline & $\theta$ & 3.2272 & 0.0222 & 1.1461 & 0.9516 \\
\hline & $\alpha$ & 0.7471 & 0.0076 & 0.1569 & 0.9518 \\
\hline \multirow[t]{3}{*}{50} & $\beta$ & 2.2022 & 0.0113 & 0.1888 & 0.9512 \\
\hline & $\theta$ & 3.1639 & 0.0146 & 0.5757 & 0.9512 \\
\hline & $\alpha$ & 0.6848 & 0.0005 & 0.1091 & 0.9513 \\
\hline \multirow[t]{3}{*}{75} & $\beta$ & 2.0732 & 0.0082 & 0.0962 & 0.9508 \\
\hline & $\theta$ & 3.0186 & 0.0097 & 0.2294 & 0.9509 \\
\hline & $\alpha$ & 0.6365 & 0.0003 & 0.0476 & 0.9506 \\
\hline \multirow[t]{3}{*}{100} & $\beta$ & 1.9848 & 0.0051 & 0.0523 & 0.9503 \\
\hline & $\theta$ & 2.9718 & 0.0076 & 0.1713 & 0.9505 \\
\hline & $\alpha$ & 0.5982 & 0.0001 & 0.0217 & 0.9502 \\
\hline
\end{tabular}

$\mathrm{T}$ a b 1 e 4

The Optimal $\tau^{*}$ and GAV Values Based on the Results from Table 3

\begin{tabular}{|c|c|c|c|c||}
\hline$n$ & $\tau^{*}$ & $n P_{u}$ & $n P_{a}$ & Optimal GAV \\
\hline 30 & 15.0668 & 10 & 13 & 0.0343 \\
\hline 40 & 14.8619 & 13 & 17 & 0.0173 \\
\hline 50 & 14.8004 & 16 & 22 & 0.005 \\
\hline 75 & 14.4371 & 25 & 31 & 0.0018 \\
\hline 100 & 14.8201 & 34 & 41 & 0.0005 \\
\hline
\end{tabular}


5. Summary and Concluding Remarks. In this article, the failure-censored SSPALT plans are addressed assuming the Lomax distribution as a lifetime model. The estimates of the Lomax parameters and the acceleration factor were obtained. Also, the optimum designs were considered using the D-optimality principle. The SSPALT model applicability and workability is demonstrated.

Acknowledgment. This project was supported by King Saud University, Deanship of Scientific Research College of Science Research Center.

\section{Резюме}

Розглядаються частково прискорені ресурсні дослідження при покроковій зміні напружень, за яких постулюється, що час до руйнування характеризується розподілом Ломакса при цензуруванні руйнування. Отримано показники максимальної імовірності параметрів даної моделі і відповідні середньоквадратичні відхилення та розраховано довірчі інтервали параметрів із відповідними імовірностями покриття. Вивчено оптимальні варіанти проведення ресурсних випробувань. Для верифікації отриманих теоретичних результатів виконано чисельне моделювання тестових задач.

1. H. F. Martz, Reliability Theory, in: Encyclopedia of Physical Science and Technology, Vol. 14 (1992), pp. 457-474.

2. Ali A. Ismail, "Estimating the generalized exponential distribution parameters and the acceleration factor under constant-stress partially accelerated life testing with type-II censoring," Strength Mater., 45, No. 6, 693-702 (2013).

3. Ali A. Ismail, "On designing constant-stress partially accelerated life tests under time-censoring," Strength Mater., 46, No. 1, 132-139 (2014).

4. Ali A. Ismail, "Bayesian estimation under constant-stress partially accelerated life test for Pareto distribution with type-I censoring," Strength Mater., 47, No. 4, 633-641 (2015).

5. W. B. Nelson, Accelerated Testing: Statistical Models, Test Plans, and Data Analysis, John Wiley \& Sons, New York (1990).

6. G. K. Bhattacharyya and Z. Soejoeti, "A tampered failure rate model for step-stress accelerated life test," Communication in Statistics - Theory \& Methods, 18, No. 5, 1627-1643 (1989).

7. P. K. Goel, Some Estimation Problems in the Study of Tampered Random Variables, Technical Report No. 50, Department of Statistics, Carnegie-Mellon University, Pittsburgh, PA (1971).

8. M. H. DeGroot and P. K. Goel, "Bayesian and optimal design in partially accelerated life testing," Nav. Res. Logist. Quart., 16, No. 2, 223-235 (1979).

9. D. S. Bai, and S. W. Chung, "Optimal design of partially accelerated life tests for the exponential distribution under type-i censoring," IEEE Trans. Reliab., 41, No. 3, 400-406 (1992).

10. D. S. Bai, S. W. Chung, and Y. R. Chun, "Optimal design of partially accelerated life tests for the lognormal distribution under type-i censoring," Reliab. Eng. Syst. Safety, 40, 85-92 (1993).

11. A. A. Abdel-Ghaly, A. F. Attia,, and M. M. Abdel-Ghani, "The estimation problem of partially accelerated life tests for Weibull distribution by maximum likelihood method with censored data," in: Proc. of the 31st Annual Conference of Statistics, Computer Sciences and Operation Research, Cairo University, Giza, Egypt (1996), pp. 128-138. 
12. Ali A. Ismail, "Inference in the generalized exponential distribution under partially accelerated tests with progressive Type-II censoring," Theor. Appl. Fract. Mech., 59, 49-56 (2012).

13. Ali A. Ismail, On designing step-stress partially accelerated life tests under failurecensoring scheme, Proc. IMechE, Part O: J. Risk Reliab., 227, No. 6, 662-670 (2013).

14. P. W. Srivastava and N. Mittal, "Optimum step-stress partially accelerated life tests for the truncated logistic distribution with censoring," Appl. Math. Modell., 34, 3166-3178 (2010).

15. A. A. Abdel-Ghaly, A. F. Attia, and H. M. Aly, "Estimation of the parameters of Pareto distribution and the reliability function using accelerated life testing with censoring," Communication in Statistics - Simulation \& Computation, 27, No. 2, 469-484 (1998).

16. S. W. Grimshaw, "Computing Maximum likelihood estimates for the generalized Pareto distribution," Technometrics, 35, 185-191(1993).

17. H. T. Davis and M. L. Feldstein, "The generalized Pareto law as a model for progressively censored survival data," Biometrica, 66, 299-306 (1979).

18. M. M. Bugaighis, "A note on convergence problems in numerical techniques for accelerated life testing analysis," IEEE Trans. Reliab., 37, No. 3, 348-349 (1988).

19. D. S. Bai, J. G. Kim, and Y. R. Chun, "Design of failure-censored accelerated life-test sampling plans for lognormal and Weibull distributions," Eng. Opt., 21, 197-212 (1993). 